\title{
High Rate of Occult Urolithiasis in Normocalcemic Primary Hyperparathyroidism
}

\author{
Alyne Layane Pereira Lemos ${ }^{a}$ Sergio Ricardo de Lima Andrade ${ }^{a}$ \\ Lívia Laeny Henrique Pontes $^{a}$ Patricia Moura Cravo Teixeira ${ }^{b} \quad$ Elba Bandeira ${ }^{a}$ \\ Leonardo C. Bandeira ${ }^{a}$ Francisco Bandeira ${ }^{a}$ \\ aDivision of Endocrinology, Diabetes and Metabolic Bone Diseases, Hospital Agamenon \\ Magalhães, University of Pernambuco Medical School, Recife, Brazil; bivision of Radiology, \\ Hospital Agamenon Magalhães, University of Pernambuco Medical School, Recife, Brazil
}

\section{Keywords}

Primary hyperparathyroidism $\cdot$ Normocalcemia $\cdot$ Nephrolithiasis

\begin{abstract}
Introduction: Normocalcemic primary hyperparathyroidism (NPHPT) is characterized by elevations in serum parathyroid hormone levels in the presence of normal serum calcium concentrations after exclusion of secondary hyperparathyroidism. We have previously demonstrated no differences in the prevalence of clinically active urolithiasis between NPHPT and hypercalcemic asymptomatic PHPT, and that it is significantly higher in postmenopausal osteoporotic women with NPHPT in comparison to women with normal serum PTH and calcium concentrations. Few studies have addressed the occurrence of silent or occult kidney stones in asymptomatic hypercalcemic PHPT, but no data are available for NPHPT. Objective: To determine the presence of occult urolithiasis in NPHPT patients using routine abdominal ultrasonography. Methods and Results: We studied 35 patients with NPHPT (mean age $63.2 \pm 10.7$ years, 96\% women; serum PTH $116.5 \pm 39.2 \mathrm{pg} / \mathrm{mL}, 25 \mathrm{OHD} 38.5 \pm 6.82 \mathrm{ng} / \mathrm{mL}$, total calcium $9.1 \pm 0.56$ $\mathrm{mg} / \mathrm{dL}$; albumin $4.02 \pm 0.37 \mathrm{~g} / \mathrm{dL} ; \mathrm{BUN} 34.35 \pm 10.23 \mathrm{mg} / \mathrm{dL} ; p=3.51 \pm 0.60 \mathrm{mg} / \mathrm{dL}$; estimated glomerular filtration rate $88.44 \pm 32.45 \mathrm{~mL} / \mathrm{min} / 1.73 \mathrm{~m}^{2}$, and 24 -h urinary calcium excretion $140.6 \pm 94.3 \mathrm{mg} / 24$ h). The criteria for the diagnosis of NPHPT were as follows: serum PTH above the reference range $(11-65 \mathrm{pg} / \mathrm{mL})$, normal albumin-corrected serum calcium concentrations, normal 24-h urinary calcium excretion, serum $25 \mathrm{OHD}$ above $30 \mathrm{ng} / \mathrm{mL}$, estimated GFR (MDRD) above $60 \mathrm{~mL} / \mathrm{min} / 1.73 \mathrm{~m}^{2}$ (with the exclusion of medications such as thiazide diuretics, lithium, bisphosphonates, and denosumab), a history of clinical symptoms of urolithiasis, and a family history of kidney stones. Thirty-five patients were evaluated and 25 of them met the inclusion criteria. Five patients presented nephrolithiasis corresponding to $20 \%$ of the study
\end{abstract}




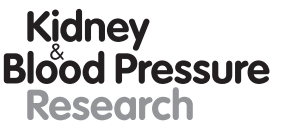

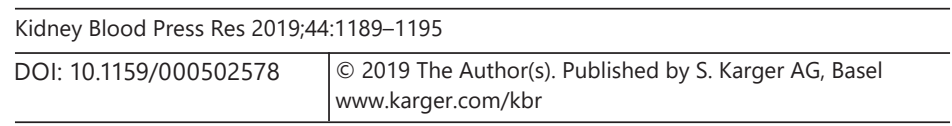

Lemos et al.: High Rate of Occult Urolithiasis in NPHPT

population. There were no statistically significant differences in any of the clinical or laboratory variables studied between patients with or without urolithiasis, although mean serum PTH levels were higher in patients with stones (180.06 \pm 126.48 vs. $100.72 \pm 25.28 \mathrm{pg} / \mathrm{mL}, p=0.1$ ). The size of the stones ranged from 0.6 to $0.9 \mathrm{~cm}$ and all of the stones were located in the renal pelvis. Conclusion: We found a high prevalence of occult kidney stones in NPHPT patients, similar to what is observed in clinically manifested urolithiasis, in hypercalcemic PHPT.

(C) 2019 The Author(s)

Published by S. Karger AG, Basel

\section{Introduction}

Normocalcemic primary hyperparathyroidism (NPHPT) is characterized by elevated serum parathyroid hormone concentrations and normal levels of serum calcium. It is necessary to exclude secondary causes of PTH elevation, such as renal disease, hypovitaminosis D, malabsorption, and use of medications that alter calcium homeostasis, such as thiazide diuretics and lithium [1]. We have previously demonstrated no differences in the prevalence of clinically active urolithiasis between NPHPT and hypercalcemic asymptomatic PHPT, and that it is significantly higher in postmenopausal osteoporotic women with NPHPT than in women with normal serum PTH and calcium concentrations. Few studies have addressed the occurrence of silent or occult kidney stones in asymptomatic hypercalcemic PHPT, but no data are available for NPHPT [2].

\section{Materials and Methods}

Thirty-five patients with NPHPT were studied (mean age $63.2 \pm 10.7$ years, $96 \%$ women). The diagnosis of NPHPT was based on the following criteria: serum PTH above the reference range (normal: $10-65 \mathrm{pg} / \mathrm{mL}$ ) and serum calcium in the normal range $(8.8-10.5 \mathrm{mg} / \mathrm{dL}$ ), estimated glomerular filtration rate (eGFR) $>60 \mathrm{~mL} / \mathrm{min} / 1.73 \mathrm{~m}^{2}$, serum $250 \mathrm{HD}>30 \mathrm{ng} / \mathrm{mL}$, and no treatment with thiazide diuretics, lithium, or antiresorptive agents. We excluded patients with a history of urolithiasis.

Patients who agreed to participate, after signing the informed consent form, answered a questionnaire and underwent a complete physical examination.

After an overnight fast, blood was drawn for laboratory tests, including serum PTH, $250 H D$, total calcium, albumin, phosphorus, BUN, and creatinine, as well as 24-h urinary calcium. Measurement of PTH and 250HD was done by electroquimoluminescent assay (Architect i2000 Abbott, USA) and 24-h urinary calcium was assessed by calorimetry. eGFR was calculated using the MDRD equation.

Urinary tract ultrasonogram (USG) was performed using transducers from 3 to $7 \mathrm{MHz}$ (HD7 EX Phillips, The Netherlands) allowing evaluation of the entire kidney. The patient was positioned in left and right lateral decubitus, and renal length and echogenicity and the presence, number, and position of renal calculi were evaluated. Calculi smaller than $3 \mathrm{~mm}$ were not considered as they may not produce a posterior acoustic shadow as larger ones do and thus lead to difficulties in the diagnosis [3].

\section{Statistical Analysis}

Data were presented as absolute and percentage frequencies for categorical variables and as means and SD for numerical variables. The Mann-Whitney test was used to compare those with or without renal stones in relation to numerical variables and the choice of the test was based on the number of cases with complications. 
Kidney

Blood Pressure

Research

Table 1. General characteristics of the study patients

\begin{tabular}{l|l}
\hline Kidney Blood Press Res 2019;44:1189-1195 \\
\hline DOI: 10.1159/000502578 & $\begin{array}{l}\text { ○ 2019 The Author(s). Published by S. Karger AG, Basel } \\
\text { www.karger.com/kbr }\end{array}$ \\
\hline
\end{tabular}

Lemos et al.: High Rate of Occult Urolithiasis in NPHPT

\begin{tabular}{lc}
\hline Age, years & $63.28 \pm 10.76$ \\
Serum PTH, pg/mL & $116.58 \pm 39.20$ \\
Serum $250 H D, n g / m L$ & $64.97 \pm 6.82$ \\
Serum calcium, mg/dL & $9.11 \pm 0.56$ \\
Serum albumin, g/dL & $4.02 \pm 0.37$ \\
Serum phosphorus, mg/dL & $3.50 \pm 0.60$ \\
BUN, mg/dL & $34.35 \pm 10.23$ \\
Serum creatinine, mg/dL & $0.70 \pm 0.13$ \\
eGFR $^{\mathrm{a}}$, mL/min/1.73 m & \\
Urinary pH & $88.44 \pm 32.65$ \\
24-h urinary calcium excretion, mg & $5.8 \pm 0.3$ \\
& $140.64 \pm 94.37$
\end{tabular}

Data are presented as means \pm SD. ${ }^{\text {a }}$ Estimated using the MDRD formula.

Table 2. Differences between patients with or without stones

\begin{tabular}{lccc}
\hline & \multicolumn{2}{l}{ Kidney stones } & \\
\cline { 2 - 3 } & yes & & \\
& & no & \multirow{2}{*}{0.705} \\
Age, years & $60.0 \pm 15.20$ & $64.10 \pm 9.70$ & 0.660 \\
Weight, kg & $66.42 \pm 13.26$ & $63.18 \pm 11.62$ & 0.110 \\
Serum PTH, pg/mL & $180.06 \pm 126.48$ & $100.72 \pm 25.28$ & 0.629 \\
Serum 25OHD, ng/mL & $36.68 \pm 2.61$ & $39.84 \pm 7.43$ & 0.125 \\
Serum calcium, mg/dL & $9.46 \pm 0.58$ & $9.03 \pm 0.54$ & 0.750 \\
Serum albumin, g/dL & $4.00 \pm 0.51$ & $4.03 \pm 0.34$ & 0.471 \\
Serum phosphorus, mg/dL & $3.28 \pm 0.19$ & $3.56 \pm 0.66$ & 0.497 \\
BUN, mg/dL & $32.8 \pm 12.62$ & $34.74 \pm 9.90$ & 0.723 \\
Serum creatinine, mg/dL & $0.68 \pm 0.08$ & $0.70 \pm 0.15$ & 0.860 \\
eGFR ${ }^{2}$ mL/min/1.73 m ${ }^{2}$ & $87.4 \pm 12.57$ & $88.7 \pm 36.23$ & 0.758 \\
Urinary pH & $5.7 \pm 0.2$ & $5.9 \pm 0.3$ & 0.371 \\
24-h urinary calcium excretion, mg & $155.8 \pm 65.09$ & $136.85 \pm 101.4$ & \\
\hline
\end{tabular}

Data are presented as means \pm SD. ${ }^{\text {a }}$ Estimated using the MDRD formula.

The statistical analysis was based on a 5\% margin of error. Calculations encompassed the mean, SD, and application of the comparison of variables between the groups with and without nephrolithiasis. The data was entered into an Excel worksheet and the software used to obtain the statistical calculations was IBM - SPSS, version 23.

\section{Results}

Of the 36 patients with NPHPT who were recruited, 25 met the inclusion criteria and were included in the statistical analysis. Two patients were excluded because they presented an eGFR of less than $60 \mathrm{~mL} / \mathrm{min}, 3$ patients were excluded because they presented serum levels of $250 \mathrm{HD}$ below $30 \mathrm{mg} / \mathrm{mL}$, and the other patients were excluded owing to incomplete data or discontinuation of clinical follow-up.

Table 1 summarizes the characteristics of the study population. The mean age of the patients was $63.28 \pm 10.76$ years, with no difference between patients with and without renal calculi; $88 \%$ of the patients were going through menopause. Only 2 male patients were selected, and 1 of them was excluded because of renal dysfunction. The mean values were as 


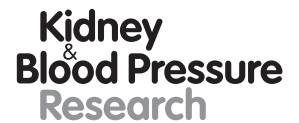

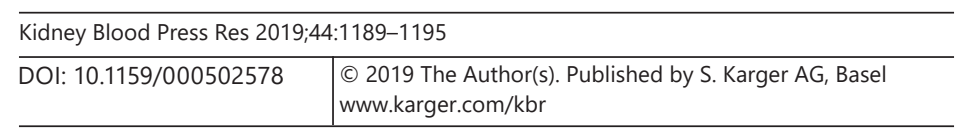

Lemos et al.: High Rate of Occult Urolithiasis in NPHPT

follows: serum PTH, $116.58 \pm 39.20 \mathrm{pg} / \mathrm{mL} ; 250 \mathrm{HD}, 38.52 \mathrm{ng} / \mathrm{mL}$; albumin-corrected serum calcium, $9.11 \pm 0.56 \mathrm{mg} / \mathrm{dL}$; and 24 -h urinary calcium, $140.64 \pm 94.37 \mathrm{mg} / 24 \mathrm{~h}$.

There were no statistically significant differences regarding the mean age, weight, MDRD and laboratory tests, including urinary $\mathrm{pH}$, between patients with and without renal calculi, as shown in Table 2.

Of the 25 patients studied, 5 presented a renal calculus identified in the USG of the urinary tract, corresponding to $20 \%$ of the cases described. Three patients had a single stone, ranging in size from 0.6 to $0.9 \mathrm{~cm}$. Two patients had multiple renal stones, with the largest being 0.9 cm in both kidneys, but 1 of them also presented nephrocalcinosis.

Patients with nephrolithiasis had higher serum PTH and serum calcium values (180.06 \pm 126.48 vs. $100.72 \pm 25.28 \mathrm{pg} / \mathrm{mL}$ and $9.46 \pm 0.58 \mathrm{vs} .9 .03 \pm 0.54 \mathrm{mg} / \mathrm{dL})$, but these differences were not statistically significant.

There were no significant differences between the groups with and without stones regarding obesity or metabolic syndrome as additional risk factors for stone formation (BMI $27.6 \pm 5.7$ vs. $26.8 \pm 6.2 ; p=0.2$, and WC $94.5 \pm 3.2$ vs. $95.2 \pm 2.8 \mathrm{~cm} ; p=0.3$ ).

\section{Discussion}

Nephrolithiasis is a common complication of hypercalcemic primary hyperparathyroidism [4]. This study identified the presence of a renal calculus in $20 \%$ of the patients with the normocalcemic form, similar to what has been reported in the literature when evaluating symptomatic nephrolithiasis in mild normocalcemic or hypercalcemic patients $[5,6]$.

With respect to the general population, data from the National Health and Nutrition Examination Survey (NHANES) from 2007 to 2010 reported a prevalence of renal calculi in the USA of $10.6 \%$ in men and 7.1\% in women [7]. In Europe, this prevalence is 5-9\% [8] and in Brazil it is 6\% [9]. In our study, in patients with NPHPT, the prevalence was $20 \%$; this is much higher than in the general population, suggesting the impact of NPHPT on the increased risk of nephrolithiasis.

The incidence of primary hyperparathyroidism increases with age, with a higher prevalence in postmenopausal women [10]. About $88 \%$ of the study participants were postmenopausal women who were diagnosed with NPHPT during the investigation for osteoporosis. This data is consistent with findings in the literature regarding the diagnosis of NPHPT. Lowe et al. [11], in a study set out to characterize the population of normocalcemic hyperparathyroidism after ruling out the possibility of secondary causes. Thirty-seven patients were identified with this condition, with most of them being women. Of these, 5 (14\%) had symptomatic nephrolithiasis and 21 (57\%) had osteoporosis at at least 1 site and $11 \%$ had fragility fractures [11].

Ejlsmark-Svensson et al. [12], using computerized tomography, showed a 23\% prevalence rate of renal calcifications with the same gender frequency in patients with hypercalcemic PHPT. Of these, $12 \%$ had common nephrolithiasis, $12 \%$ had nephrocalcinosis, and 1\% had both nephrolithiasis and nephrocalcinosis. Impaired renal function was also common in PHPT, but it was not associated with renal calcifications [12].

In a cross-sectional analysis of 96 asymptomatic hypercalcemic PHPT patients, an increased incidence of occult urolithiasis was observed, representing $21 \%$ of the sample. Patients with stones had significantly higher serum 1,250H2D concentrations as well as higher 24-h urinary calcium levels compared to those without stones [13].

Tuna et al. [6] compared the complications of PTH in normocalcemic and hypercalcemic patients. The studied population consisted of $36(12 \%)$ men and 271 (88\%) women. Twentythree of the patients were diagnosed with NPHPT and 284 were diagnosed with the hyper- 


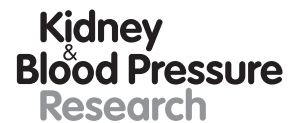

Kidney
Blood Pressure
Research \begin{tabular}{l|l}
\hline Kidney Blood Press Res 2019;44:1189-1195 \\
\hline DOI: 10.1159/000502578 & $\begin{array}{l}\text { @ 2019 The Author(s). Published by S. Karger AG, Basel } \\
\text { www.karger.com/kbr }\end{array}$ \\
\hline
\end{tabular}

Lemos et al.: High Rate of Occult Urolithiasis in NPHPT

calcemic form. There were no significant differences in terms of age, sex, the prevalence of hypertension, low bone mineral density, and renal calculi between groups. Nephrolithiasis was found in $15.4 \%$ of the normocalcemic patients and $19.4 \%$ of the hypercalcemic ones [6].

At our institution, other studies have evaluated the presence of complications associated with primary normocalemic hyperparathyroidism. Marques et al. [14] retrospectively evaluated the occurrence of hyperparathyroidism in 156 female patients with osteoporosis and found that $14 \%$ of the patients had primary normocalemic hyperparathyroidism. Among these patients, the presence of symptomatic nephrolithiasis was $28.6 \%$, in contrast to only $0.7 \%$ of non-NPHPT carriers [14]. Amaral et al. [2] compared clinical and laboratory data among patients with normal and hypercalcemic primary hyperparathyroidism. Seventy patients were studied (i.e., 33 normocalcemic and 37 hypercalcemic patients). The frequency of symptomatic nephrolithiasis was $18.2 \%$ in the normocalcemic patients and $18.9 \%$ in the hypercalcemic patients [2].

In our study, there were no significant statistical differences in the biochemical tests between the 2 groups; however, there was a trend toward higher serum PTH levels and calcium elevation in patients with nephrolithiasis. The 24-h urinary calcium was similar in the 2 groups, suggesting that renal stone formation in the patient with primary hyperparathyroidism may be associated with other factors, not only hypercalcemia and hypercalciuria $[15,16]$. This is justified by the similarity in the prevalence of renal calculus among normocalcemic and hypercalcemic patients, as described in the study by Amaral et al. [2].

The higher rate of occult nephrolithiasis in patients with NPHPT suggests that renal complications associated with primary hyperparathyroidism may be an early event. This findings thus reinforce the importance of the diagnosis and follow-up of patients with NPHPT for the early identification of complications that were previously associated only with hypercalcemic PHPT [6].

Concerns regarding NPHPT arise from the increased prevalence of this condition over the years. Kontogeorgos et al. [17] showed that the prevalence of NPHPT was 2\% in 1995 and $11 \%$ in 2008 . With the increase in prevalence come an increase in the appearance of complications and resulting increased costs for health services.

In the present study USG of the urinary tract was performed like in most studies investigating renal stones in hypercalcemic PHPT [2]. In addition to being a low-cost examination, it does not expose the patient to radiation. Its sensitivity varies depending on the location and size of the calculi. Our study evaluated calculi that were found in the renal pelvis, which in most cases are asymptomatic. Migratory or localized calculi in the ureter are usually accompanied by signs and symptoms such as hematuria, dysuria, and abdominal pain. Renal calculi of less than $3 \mathrm{~mm}$ were not considered in this study. The USG is unable to identify stones smaller than $3 \mathrm{~mm}$, which may be confused with artifacts or increased echogenicity of renal sinus fat. Computed tomography (CT) allows visualization of these calculi since this method also measures their density. However, CT should not be used routinely due to the risk of exposure to radiation, and it is reserved in cases with a high clinical suspicion of nephrolithiasis and normal USG and abdominal x-ray [3].

In conclusion, we found a high prevalence of occult kidney stones in NPHPT patients similar to what is observed, for clinically manifested urolithiasis, in hypercalcemic PHPT.

\section{Acknowledgement}

We acknowledge P.M.C.T. of the institution radiology department who performed all of the ultrasound examinations. 


\section{Statement of Ethics}

All of the patients in this study signed an informed consent form. This study was approved by the Research Ethics Committee of the Agamenon Magalhães Hospital.

\section{Disclosure of Statement}

The authors have no conflict of interests to declare.

\section{Funding Sources}

No funding sources.

\section{Author Contributions}

Research design: A.L.P.L., S.R.L.A., L.L.H.P., L.C.B., and F.B. Data collection: A.L.P.L., S.R.L.A., L.L.H.P., P.M.C.T., E.B., and L.C.B. Data analysis: E.B., L.C.B. and, F.B. Article development: A.L.P.L., E.B., L.C.B., and F.B. Mentorship: F.B.

\section{References}

1 Yener Ozturk F, Erol S, Canat MM, Karatas S, Kuzu I, Dogan Cakir S, et al. Patients with normocalcemic primary hyperparathyroidism may have similar metabolic profile as hypercalcemic patients. Endocr J. 2016;63(2):111-8.

2 Amaral LM, Queiroz DC, Marques TF, Mendes M, Bandeira F. Normocalcemic versus hypercalcemic primary hyperparathyroidism: more stone than bone? J Osteoporos. 2012;2012:128352.

3 Vijayakumar M, Ganpule A, Singh A, Sabnis R, Desai M. Review of techniques for ultrasonic determination of kidney stone size. Res Rep Urol. 2018;10:57-61.

4 Khan AA, Hanley DA, Rizzoli R, Bollerslev J, Young JE. Primary hyperparathyroidism: review and recommendations on evaluation, diagnosis, and management - a Canadian and international consensus. Osteoporos Int. 2017 Jan;28(1):1-19.

5 Suh JM, Cronan JJ, Monchik JM. Primary hyperparathyroidism: is there an increased prevalence of renal stone disease? AJR Am J Roentgenol. 2008 Sep;191(3):908-11.

6 Tuna MM, Çalışkan M, Ünal M, Demirci T, Doğan BA, Küçükler K, et al. Normocalcemic hyperparathyroidism is associated with complications similar to those of hypercalcemic hyperparathyroidism. J Bone Miner Metab. 2016 May;34(3):331-5.

7 Tang J, Mettler P, McFann K, Chonchol M. The association of prevalent kidney stone disease with mortality in US adults: the National Health and Nutrition Examination Survey III, 1988-1994. Am J Nephrol. 2013; 37(5):501-6.

8 López M, Hoppe B. History, epidemiology and regional diversities of urolithiasis. Pediatr Nephrol. 2010 Jan;25(1):49-59.

9 Filgueiras Pinto RS, Almeida JR, Kang HC, Rosa ML, Lugon JR, Rosa G, et al. Metabolic syndrome and associated urolithiasis in adults enrolled in a community-based health program. Fam Pract. 2013 Jun;30(3): 276-81.

10 Walker MD, Silverberg SJ. Primary hyperparathyroidism. Nat Rev Endocrinol. 2018 Feb;14(2):115-25.

11 Lowe H, McMahon DJ, Rubin MR, Bilezikian JP, Silverberg SJ. Normocalcemic primary hyperparathyroidism: further characterization of a new clinical phenotype. J Clin Endocrinol Metab. 2007 Aug;92(8): 3001-5.

12 Ejlsmark-Svensson H, Bislev LS, Rolighed L, Sikjaer T, Rejnmark L. Predictors of Renal Function and Calcifications in Primary Hyperparathyroidism: A Nested Case-Control Study. J Clin Endocrinol Metab. 2018 Sep;103(9):3574-83.

13 Tay YD, Liu M, Bandeira L, Bucovsky M, Lee JA, Silverberg SJ, et al. Occult urolithiasis in asymptomatic primary hyperparathyroidism. Endocr Res. 2018 May;43(2):106-15. 
14 Marques TF, Vasconcelos R, Diniz E, Rêgo D, Griz L, Bandeira F. Normocalcemic primary hyperparathyroidism in clinical practice: an indolent condition or a silent threat? Arq Bras Endocrinol Metab. 2011;(55): $314-7$.

15 Vezzoli G, Macrina L, Magni G, Arcidiacono T. Calcium-sensing receptor : evidence and hypothesis for its role in nephrolithiasis. Urolithiasis. 2019 Feb;47(1):23-33.

16 Li H, Zhang J, Long J, Shi J, Luo Y. Calcium-sensing receptor gene polymorphism (rs7652589) is associated with calcium nephrolithiasis in the population of Yi nationality in Southwestern China. Ann Hum Genet. 2018 Sep;82(5):265-71.

17 Kontogeorgos G, Trimpou P, Laine CM, Oleröd G, Lindahl A, Landin-Wilhelmsen K. Normocalcaemic, vitamin D-sufficient hyperparathyroidism - high prevalence and low morbidity in the general population: A long-term follow-up study, the WHO MONICA project, Gothenburg, Sweden. Clin Endocrinol (Oxf). 2015 Aug;83(2):277-84. 